Academic Platform Journal of Engineering and Science

journal homepage: http://apjes.com/

\title{
IoT Teknolojilerini Kullanan Afet Sonrası Yönetim Sistemi
}

\author{
${ }^{1}$ Kerem Küçük, ${ }^{* 2}$ Cüneyt Bayılmış, ${ }^{3}$ Ahmet Furkan Sönmez, ${ }^{4}$ Sezgin Kaçar \\ ${ }^{1}$ Kocaeli Üniversitesi Mühendislik Fakültesi, Bilgisayar Mühendisliği, Kocaeli, kkucuk@kocaeli.edu.tr \\ ${ }^{2}$ Sakarya Üniversitesi, Bilgisayar ve Bilişim Bilimleri Fak., Bilgisayar Mühendisliği, Sakarya, cbayilmis@ sakarya.edu.tr \\ ${ }^{3}$ Sakarya Üniversitesi, Bilgisayar ve Bilişim Bilimleri Fakültesi, Bilgisayar Mühendisliği, Sakarya, \\ furkansonmez@sakarya.edu.tr \\ ${ }^{4}$ Sakarya Uygulamalı Bilimler Üniversitesi Teknoloji Fakültesi, Elektrik-Elektronik Mühendisliği, Sakarya, \\ skacar@sakarya.edu.tr
}

Araştırma Makalesi

Geliş Tarihi: 25.10 .2018

Kabul Tarihi: 31.12 .2018

$\ddot{O} z$

Deprem, sel vb. afet olaylarından sonra can ve mal kaybı gibi afetin etkilerini azaltmak için afet bölgesinden doğru ve hızlı bilgi edinilmesi büyük önem arz etmektedir. Bu bilgi afet sonrası yönetim sistemlerinin de etkinliğini arttırmaktadır. Günümüzde nesnelerin interneti teknolojisi akıllı şehir, akıllı ev, enerji yönetimi, trafik optimizasyonu vb. çok geniş uygulama alanına sahiptir. Bu çalışmada nesnelerin interneti teknolojilerini kullanan, bulanık mantık temelli karar destek sistemine sahip bir afet sonrası yönetim sistemi sunulmaktadır. Bu sistem, nesnelerin interneti teknolojilerinden yararlanarak afetten etkilenen hasarlı bina, etkilenen kişi sayısı gibi bilgilerin elde edilmesi ile afet sonrası yönetim sisteminin kurtarma personeli, ekipman, araç vb. kaynakları etkili bir şekilde yönetmesini ve planlamasını amaçlanmaktadır. Önerilen sistemin başarım değerlendirmesi 7 baz istasyonu, $50 \mathrm{WiFi}$ bağlantı noktası ve 10 IoT nesnesi içeren örnek bir senaryo üzerinde sunulmuştur. Bina hasar durumları ile afet bölgesindeki insan yoğunluğuna ait bilgiler bulanık mantık temelli karar destek sistemi ile üç farklı renkte görselleştirilmiş ve sınıflandirılmıştır.

Anahtar Kelimeler: Nesnelerin İnterneti, Kalabalık Algılama, Afet Sonrası Yönetim Sistemi

\section{Post-Disaster Management System Using IoT Technologies}

\author{
${ }^{1}$ Kerem Kucuk, ${ }^{* 2}$ Cuneyt Bayilmis, ${ }^{3}$ Ahmet Furkan Sonmez, , ${ }^{4}$ Sezgin Kacar \\ ${ }^{1}$ Kocaeli University Faculty of Engineering, Department of Computer Engineering, Kocaeli, kkucuk@kocaeli.edu.tr \\ ${ }^{2}$ Sakarya University Faculty of Computer and Information Sciences, Department of Computer Engineering, Sakarya, \\ cbayılmıs@sakarya.edu.tr \\ ${ }^{3}$ Sakarya University Faculty of Computer and Information Sciences, Department of Computer Engineering, Sakarya, \\ furkansonmez@sakarya.edu.tr \\ ${ }^{4}$ Sakarya Applied Sciences University, Faculty of Technology, Department of Electrical and Electronics Engineering, \\ Sakarya, skacar@sakarya.edu.tr
}

\begin{abstract}
It is of great importance to obtain accurate and fast information from the disaster area in order to reduce the effects of disaster such as loss of life and property after a disaster like earthquake, flood, etc. is occurred. This information also increases the effectiveness of post-disaster management systems. Nowadays, internet of things technology has a wide range of applications including smart city, smart home, energy management, traffic optimization and so on. In this study, a post-disaster management system using internet of things technologies that possesses a fuzzy logic based decision support system is presented. This system aims to manage and plan resources of a post-disaster management system such as rescue personal, equipment, vehicles etc. effectively by obtaining information about the number of people and damaged building affected by the disaster. The performance evaluation of the proposed system is presented on an example scenario including 7 base stations, $50 \mathrm{WiFi}$ connection points and 10 IoT objects. The information on the building damage situation and the human density in the disaster area has been visualized and classified in three different colors with fuzzy logic based decision support system.
\end{abstract}

Sorumlu Yazar: *22Sakarya Üniversitesi, Bilgisayar ve Bilişim Bilimleri Fakültesi, Bilgisayar Mühendisliği Bölümü, cbayilmis@sakarya.edu.tr, 02642956483

"Bu çalışma ISHAD2018'de sunulan bildiriden türetilmiştir." 
Keywords: Internet of Things (IoT), Crowd Sensing, Post-Disaster Management System

\section{GÍRİs}

Deprem, sel vb. afet olayları ekonomik, altyapı, ulaşım sistemi, insan hayatı gibi kayıplara yol açmaktadır. Bu kayıpların azaltılmasında afet yönetimi önemli bir role sahiptir. Afet yönetimi, arama-kurtarma ekipleri, araç-gereç, yardım malzemesi gibi kaynakların yönetimi ve planlamasını gerçekleştirir [1-3]. Günümüzde akıllı ev uygulamalarından akıllı şehirlere, enerji yönetiminden uzaktan izleme sistemlerine, sağlık uygulamalarından ulaşım sistemlerinin kontrol ve optimizasyonuna kadar çok geniş uygulama alanına sahip olan nesnelerin interneti (Internet of Things, IoT) teknolojileri afet yönetim sistemlerinin etkinliğinin arttırılması amacıyla da kullanılmaktadır [4-6]. Nesnelerin interneti algılama ve veri işleme yeteneğine sahip, birbirleri ve internet ile haberleşebilen cihazların oluşturduğu bir ekosistemdir.

IoT teknolojilerini kullanan bir afet yönetim sistemi afet sonrası etkilerin azaltılmasında katkı sağlayabilir. IoT teknolojilerinin kullanımı ile afet bölgesi ve afetten etkilenenler hakkında hızlı ve doğru bilgi sahibi olunur. Böylelikle kurtarma personeli, ekipman, araçlar vb. kaynaklar daha etkin bir şekilde yönetilebilir. Özetle, IoT teknolojilerinin kullanılması afet sonrası yönetim sürecini kolaylaştırır [3].

IoT teknolojilerinin afet yönetimi alanında kullanımı ile ilgili literatürde çalışmalar bulunmaktadır. K. Küçük ve ark. afet yönetim süreçlerinin daha etkin yürütülmesi için bina hasar durumunu ölçen IoT nesneleri ile GSM, WiFi gibi haberleşme teknolojilerine dayalı olarak kişi yoğunluğunu dikkate alan bir yönetim platformu önermektedir [1]. Sakhardande ve ark. WiFi haberleşme teknolojisi kullanan Ardunio tabanlı akıllı modüllere sahip bir uzaktan izleme sistemi geliştirmişlerdir. $\mathrm{Bu}$ sistem ile akıllı şehir izleme uygulamalarıyla afet yönetim sistemlerinin birlikte kullanımını önermişlerdir [3]. Poslad ve ark. doğal afetler durumunda kriz yönetimi için IoT temelli bir erken uyarı sistemi geliştirilmiştir [7]. Benkhelifa ve ark. ise afet ile ilgili bilgi toplama ve veri paylaşımına dikkat çekmektedir. Aynı zamanda çalışmalarında kablosuz algılayıcı ağ teknolojisine dayalı afet yönetim projesi sunmaktadırlar [8]. Bir başka çalışmada ise kablosuz algılayıcı ağ teknolojisine dayalı olarak orman yangın durumlarının uzaktan izlendiği bir afet yönetim sistemi modeli önerilmektedir [9]. Afet durumlarında en önemli problemlerden biri olan haberleşme altyapısının hasarı durumunda afet sonrası yönetim için IoT teknolojilerine dayalı iletişim önerilmektedir [10].

$\mathrm{Bu}$ çalışma afet sonrası yönetim sistemlerinin etkinlik ve verimliliğini arttırmak için IoT teknolojilerinin kullanılabileceğini göstermeyi amaçlamaktadır. Bu amaç doğrultusunda, IoT teknolojilerine dayalı bir afet sonrası yönetim sistemi sunulmaktadır. Önerilen sistem (i) bina, köprü vb. konumlandırıldığı yapının hasar durumunu tespit edebilecek IoT nesnesi, (ii) IoT nesnelerinden hasar bilgisi ile birlikte hücresel ve WiFi bağlantısı gibi diğer IoT teknolojilerinden toplanan verilerin depolanmasını, analizini ve görselleştirilmesini sağlayan Afet Sonrası IoT Yönetim Platformu, (iii) bina hasar bilgisi, afet bölgesindeki insan yoğunluğu gibi bilgileri dikkate alarak kaynakların etkin yönetimini sağlayacak bulanık mantık temelli karar destek sistemi olmak üzere üç temel bileşenden oluşmaktadır.

IoT nesnesi, ivmeölçer, barometre gibi sensörler, GSM/WiFi gibi iletişim üniteleri, mikroişlemci ve benzeri birimlerden oluşan gömülü sistemdir. IoT nesnesinin görevi konumlandırıldığı yapının hasar durumu hakkında veri toplamak ve toplanan verileri buluta göndermektir. Afet bölgesindeki insan yoğunluğunun ise o bölgedeki baz istasyonuna bağlı kullanıcı sayısının operatörlerden temini ve yerel WiFi bağlantıları üzerinden yaklaşık olarak elde edilmesi varsayılmaktadır. Afet Sonrası IoT Yönetim Platformu ise IoT-donanım ve afet bölgesindeki IoT teknolojilerini kullanan bireylerden toplanan verileri depolama, analiz ve görselleştirme işlemlerini yerine getirmektedir. Bulanık mantık temelli karar destek sistemi ise IoT nesnesinden alınan veriler ile hesaplanan bina hasar durumu, mobil kullanıcı kayıtları, WiFi bağlantı bilgileri ile afet alanındaki insan yoğunluğu bilgilerini kullanarak afetten etkilenen bölgeleri sınıflandırmaktadır. Sonuç olarak Afet Sonrası Yönetim Sistemi, afet yönetim süreçlerinin daha etkin ve verimli yönetilmesini amaçlanmaktadır.

Sunulan çalışmanın literatürdeki çalışmalardan farkları ve katkıları arasında afet bölgesinden hızlı ve doğru bilgi toplamak için gömülü sistem, GSM altyapısı ve $\mathrm{WiFi}$ bağlantısı gibi birden fazla ve farklı IoT teknolojilerinin bir arada kullanımı, IoT teknolojileri aracılığıyla toplanan verilerin daha sağlıklı analizi için karar destek sistemlerinden yararlanabileceğini göstermektir.

IoT Teknolojilerini Kullanan Afet Sonrası Yönetim Sisteminin başarım değerlendirmesinde afet bölgesi olarak Sakarya Üniversitesi kampüs alanı seçilmiş, bu alan içerisinde 7 baz istasyonu ve $50 \mathrm{WiFi}$ bağlantı noktası ile bina hasar durumlarını ölçen 10 adet IoT nesnesinin olduğu varsayılmıştır. Afet sonrası yönetim platformunda bina hasar durumları kırmız, sarı ve yeşil renkler ile 3 farklı seviyede ve insan yoğunluğu ile birlikte gösterilmiştir. Böylelikle kullanıcıların afet bölgesi hakkında daha hızlı bilgi sahibi olmaları amaçlanmaktadır.

Makalenin geri kalan kısmı aşağıdaki şekilde organize edilmiştir: Bölüm 2'de Afet Sonrası Yönetim Sistemi ve bu sistemi oluşturan üç temel bileşen ayrıntılı olarak ele alınmaktadır. Bölüm 3 'te Afet Sonrası Yönetim Sisteminin örnek bir senaryo ile değerlendirmesi yapılmaktadır. Çalışma son bölümde genel değerlendirmeler ile sonuçlandırılmaktadır. 


\section{AFET SONRASI YÖNETIM SISTEMI}

Afet Sonrası Yönetim Sisteminin Şekil 1'de sistem mimarisi verilmektedir. Şekilden görüldüğü üzere bina, köprü gibi yapılar üzerine konuşlandırılacak IoT nesnesi sahip olduğu sensörler aracılığıyla elde ettiği bina hasar durumuna ait verileri bulut aracılığıyla depolanmak, analiz edilmek ve görselleştirmek için Afet Sonrası IoT Yönetim Platformuna iletmektedir. Bu platform, yönetim sistemi kullanıcıların etkileşimde olduğu kısımdır.

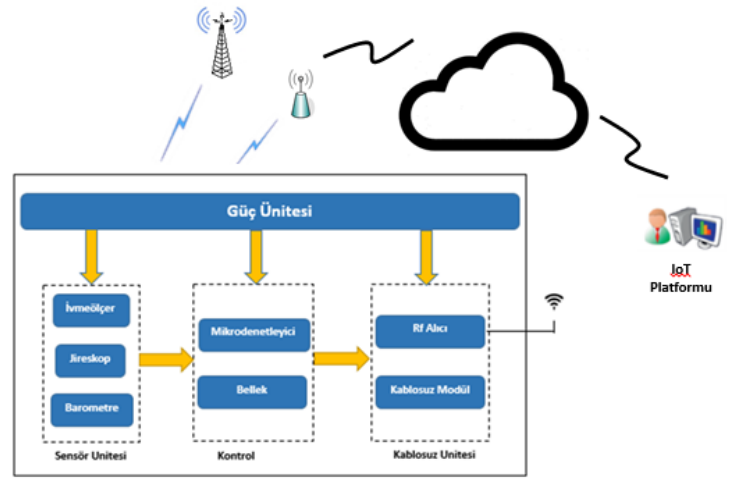

Şekil 1. Önerilen sistem mimarisi

Şekil 2'de Afet Sonrası Yönetim Sisteminin çalışmasını özetleyen basitleştirilmiş akış diyagramı sunulmaktadır. Gömülü sistemlerde en fazla enerji tüketimi kablosuz iletişim esnasında yaşanmaktadır. Bu nedenle IoT nesnesinin enerji tüketimini minimize etmek için algılanan her verinin değil, algılanan veriler arasında değişim olduğunda gönderim gerçekleştirilmektedir. Afet Sonrası Yönetim Platformu ise IoT nesnesi ve afet alanındaki insan yoğunluk bilgilerini depolar, görselleştirir ve bulanık mantık tabanlı karar destek sistemi yardımıyla analiz eder.

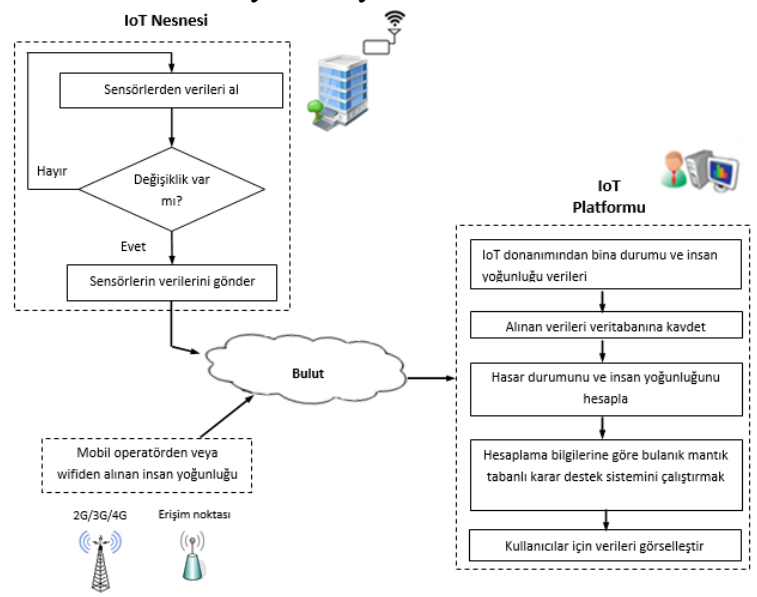

Şekil 2. Önerilen sistem basitleştirilmiş akış diyagramı

\subsection{IoT Nesnesi}

Nesnelerin internet algılama, iletişim, adresleme ve veri işleme yeteneklerine sahip olan bir ağ sistemidir. Algılayıcı, iletişim ünitesi, mikroişlemci / mikrodenetleyici vb. gibi birimleri içeren IoT-nesnesi, IoT iletişim protokolleri aracılığıyla internete veya buluta bağlanırlar. Şekil 3'te Afet Sonrası Yönetim Sisteminde kullanılan IoT nesnesinin resmi görülmektedir. Uygulamada kullanılan IoT nesnesi, mikrodenetleyici olarak Arduino MEGA, kablosuz haberleşme birimi olarak SIM900 modülüne sahip GPRS modülü ve hasar bilgisinin elde edilmesi için 3 eksenli ivmeölçer ADXL345 ile BMP180 barometre ve bataryadan oluşmaktadır. Sensörler ile IoT nesnesi yerleştirildiği binanın hasar gördüğü (yıkıldığı) yön ve yıkılma mesafe (yükseklik değişimi) gibi bilgileri algılar ve algılanan verileri IoT bağlantı protokolü aracılığıyla IoT analiz platformuna iletir. Kablosuz iletişim birimi, IoT-ünitesi ve IoT-analiz platformu arasındaki iletişimi sağlar. IoT bağlantı protokolü olarak Mesaj Kuyruk Telemetri Ulaştırma (Message Queuing Telemetry Transport, MQTT) mesajlaşma protokolü kullanılmaktadır [1].

MQTT protokolü, bant genişliği, bellek, işlemci gibi kısıtlı kaynaklara sahip IoT cihazları için tasarlanmış düşük güçlü (lightweight) bir mesajlaşma protokolüdür. 1999 yılında geliştirilen MQTT protokolü 2016 y1lında ISO standardı olarak onaylanmıştır (ISO/IEC 20922:2016). IoT ve kablosuz algılayıcı ağlar için geliştirilmiş MQTT v.31. ve MQTT-SN versiyonları bulunmaktadır. MQTT protokolü TCP / IP protokolü üzerine kurulmuştur ve IoT cihazlarının internet (bulut) bağlantısını sağlar. MQTT, bir İstemciSunucu yayın / abone mesajlaşma protokolüdür. MQTT, yayımc1, abone ve sunucu olmak üzere üç temel bileşenden oluşmaktadır. Yayımcı konu ve mesaj içeriğinden oluşan verinin üretimini, abone ise yayımc tarafindan yayılan verinin alımını ve sunucu ise yayımcı ile abone arasında bir konuya göre verinin dağıtımı işlemlerinden sorumludur. MQTT protokolünün önemli özelliklerinden biri ise 3 farklı servis kalitesi desteği sunmasıdır. MQTT protokolü akıllı şehir, enerji yönetimi, sosyal medya uygulamaları, sağlık gibi çok geniş kullanım alanına sahiptir [4, 9-12]. Bu çalışmada, yayıncı IoT nesnesi ve abone Afet Sonrası IoT Yönetim Platformudur.

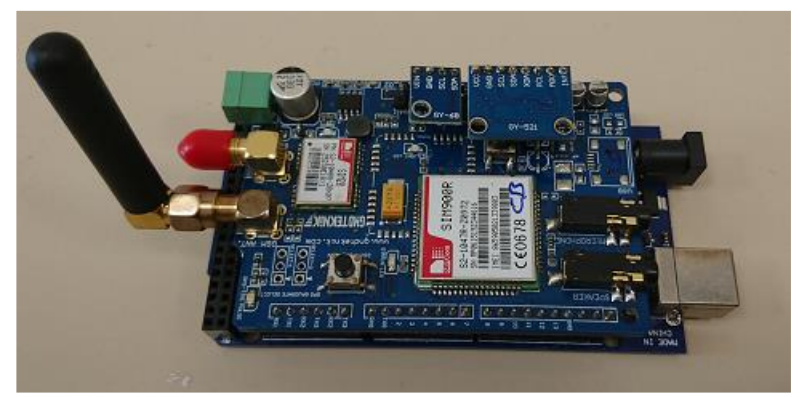

Şekil 3. IoT nesnesine ait resim

\subsection{Afet Sonrası IoT Yönetim Platformu}

Kullanıcılar ile etkileşim halindeki Afet Sonrası IoT Yönetim Platformu, IoT nesnelerinden alınan verileri depolanmasını, analiz edilmesini, görselleştirilmesini ve izlenmesini sağlar. Bir afet olayı meydana geldiğinde, afet alanı Şekil 4'te görüldüğü üzere kabaca ve renkli olarak harita üzerinde gösterilir. Ardından, renkli bölge içerisindeki 
alan büyütülerek hasar gören bina konumlandırması ve bölgedeki insan yoğunluğu ve hasar durumunu da içeren hasar bilgisinin görüldüğü ekran kesiti görülmektedir (Şekil $5)$.

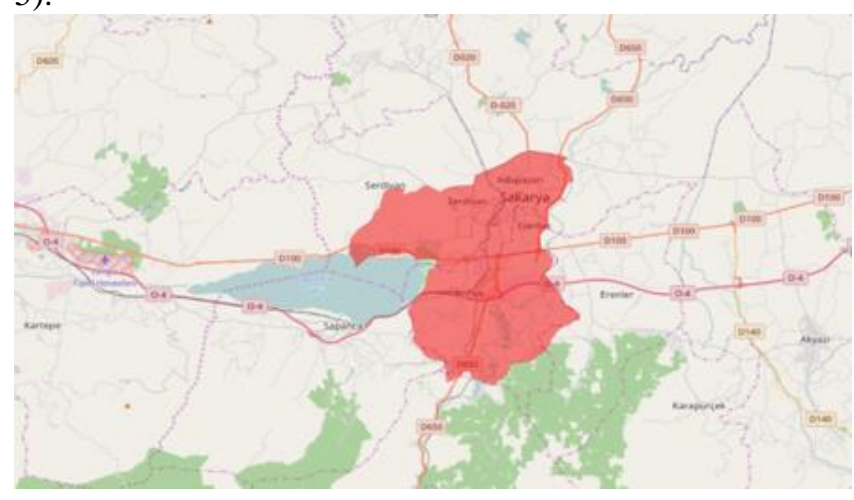

Şekil 4. Platform üzerinde afet olayının yaşandığı bölgenin görselleştirilmesi

IoT Platformunun geliştirme sürecinde HTML5, Javascript, CSS, Google Map ve Firebase teknolojileri kullanılmıştır. Google Map, API-KEY'i kullanarak projeye kolayca eklenebilir. Buna ek olarak, bu harita, belirli bir alan seçimi, renklendirme vb. pek çok özellik sunmaktadır. Firebase, mobil ve web tabanlı uygulamalar için Google tarafindan geliştirilen popüler bir bulut tabanlı platformdur. Firebase, NoSQL veri tabanı kullanarak kullanıcılar ve cihazlar arasında verileri gerçek zamanlı olarak saklar ve senkronize eder. Afet Sonrası IoT Yönetim Platformu, IoT nesnelerinin konumlandırıldığı yapıların hasar durumlarının hesaplanma prosedürü, afet alanındaki insan yoğunluğunun tahmini için kümeleme prosedürü, bu bilgilerin işlendiği bulanık tabanlı karar destek sistemi ve kullanıcı ara yüzünden oluşmaktadır.

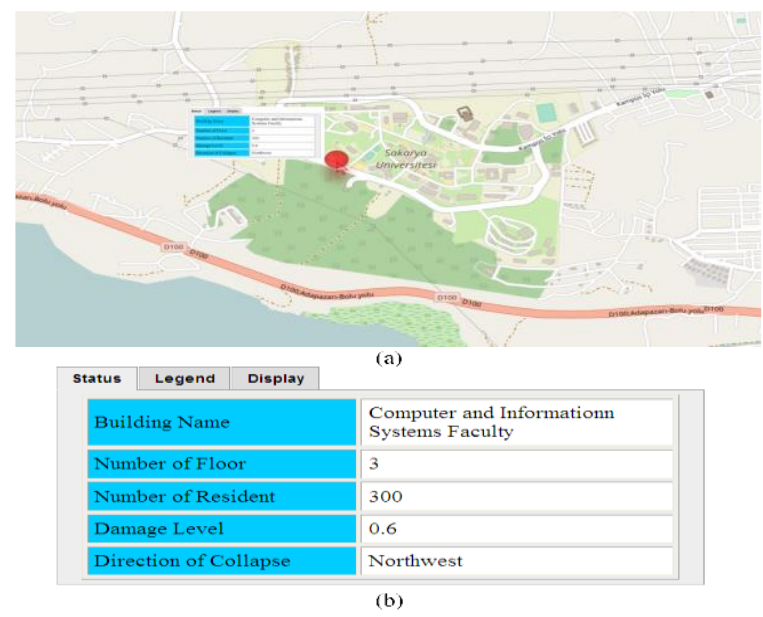

Şekil 5. Afet bölgesindeki ayrıntılı hasar bilgisi

\subsubsection{Yapıların hasar belirleme işlemi}

Bir afet olayı meydana geldikten sonra IoT nesnesinin yerleştirildiği binanın hasar seviyesinin hesaplanmasında IoT nesnesinde bulunan ivmeölçer, jiroskop sensörleri kullanılmaktadır. $\mathrm{Bu}$ sensörlerden elde edilen veriler ile binanın hasar yönü ve yıkım mesafesi gibi bilgiler elde edilmektedir $[13,14]$. Örneğin hızlanma (ivme) verileri hızın değişimini belirtir ve hız değişiminden de mesafe hesaplanır. IoT nesnesinin yerleştirildiği yapının başlangıç durumu bilindiği için yapıdaki değişim tahmin edilebilir. Mesafe; zamanın bir fonksiyonu olarak varsayılırsa $(s(t))$, hiz ve ivme şu şekilde formüle edilebilir;

$a(t)=v^{\prime}(t)=s^{\prime \prime}(t)$

IoT nesnesinde ivmeölçer sensörü olarak ADXL345 kullanılmıştır. $\mathrm{Bu}$ sensör 3 eksenli ivme ölçebilmektedir. İvmeölçer, yerçekiminin statik ve dinamik ivmesini ölçer. Binanın hasar durumunu hesaplamak için her iki ivme verisinden de yararlanılmıştır. Eğim algılama uygulamalarında statik ivme kullanılmakta iken hareket algilama uygulamalarında dinamik hizlanma kullanılmaktadır [13, 14]. Toplam statik ivme vektör uzunluğu (SA) IoT nesnesi tarafindan aşağıdaki gibi hesaplanır:

$\mathcal{S} A=\sqrt{\left(a_{x}\right)^{2}+\left(a_{y}\right)^{2}+\left(a_{z}\right)^{2}}$

Burada $a_{x}, a_{y}$, and $a_{z}$ yerçekimi statik ivme vektörünün üç bileşenidir. Benzer şekilde, toplam dinamik hızlanma vektör uzunluğu $(\mathcal{D} \mathcal{A})$ aşağıdaki gibi hesaplanır:

$\mathcal{D} \mathcal{A}=\sqrt{\left(b_{x}\right)^{2}+\left(b_{y}\right)^{2}+\left(b_{z}\right)^{2}}$

Burada $\vec{b}=\left(b_{x} b_{y} b_{z}\right)$ üç eksende yerçekimi dinamik ivme vektörüdür. Binanın yıkım esafesini hesaplamak için, toplam statik ve dinamik ivme vektörlerine göre dikey ivme şu şekilde elde edilir:

$V \mathcal{A}=\sqrt{(\mathcal{S} \mathcal{A})^{2}-(\mathcal{D} \mathcal{A})^{2}-(\mathcal{G})^{2} / 2 \mathcal{G}}$

Burada $\mathcal{G}$ yerçekimini ifade etmektedir. Buna ek olarak, aşağıdaki gibi jiroskop verilerini kullanarak binanın dönüş açısını elde edilmektedir:

$\mathcal{S W}=\sqrt{\left(w_{x}\right)^{2}+\left(w_{y}\right)^{2}+\left(w_{z}\right)^{2}}$

Burada $\vec{w}=\left(w_{x} w_{y} w_{z}\right)$ IoT biriminin dönüş vektörünün açısıdır. Burada $a(t)$ ve $a(t)$ zamanın bir fonksiyonu olarak hızlanma ve hızdır. “, " işareti zamana göre türev için kullanilır.

\subsubsection{Nüfus yoğunluğuna göre kümeleme}

İnsan yoğunluğu bilgisi, kurtarma ekiplerini yönlendirmek için önemli verilerdir. Bu yoğunluk bilgisini analiz etmek için kümeleme algoritması kullanılmıştır [15]. Y. Guo ve arkadaşlarından farklı olarak, akıllı telefonlar, şehirlerde inşa edilen baz istasyonlarına (BS) ve binalara yerleştirilen Wi-Fi 
erişim noktalarına (AP) bağlanabilir. Kümeleme için BS ve AP bağlantı verilerini göz önünde bulundurulmuştur. Bu veri seti, afet yönetim platformumuzun girişi olarak kullanılmıştır. $\mathrm{Bu}$ veriler şu şekilde tanımlanmıştır:

$$
\begin{aligned}
\mathcal{D}_{i}^{B S}=\left\{\mathcal{P} \mathcal{N}_{i}, \varphi_{i}^{B S}, \lambda_{i}^{B S}, t_{i}, \Delta t_{i}\right\}, \\
\mathcal{D}_{j}^{W F}=\left\{\mathcal{M C}_{\mathcal{A C}}, \varphi_{j}^{W F}, \lambda_{j}^{W F}, t_{j}, \Delta t_{j}\right\}
\end{aligned}
$$

Burada $\mathcal{P} \mathcal{N}_{i}$ abonenin telefon numarasıdır. $\varphi_{i}^{B S}$ ve $\lambda_{i}^{B S}$ BS'nin enlem ve boylamıdır. $t_{i}$ BS'ye abone bağlantı süresidir. $\Delta t_{i}: \mathcal{P} \mathcal{N}_{i}$ nin süresidir. $\mathcal{M} \mathcal{A} \mathcal{C}_{j}$ kullanıcının mac numarasıdır., $\varphi_{j}^{W F}$ ve $\lambda_{j}^{W F}$ Ap'nin enlem ve boylamıdır. $t_{j}$ erişim noktasına olan kullanıcı bağlantı süresidir. $\Delta t_{j}$ : $\mathcal{M} \mathcal{A C}_{j}$ ' in kullanım süresidir. BS ve AP bağlantısı tarafindan yönetilen bağlantı veri seti düzensizdir. $\mathrm{BS}$ veya $\mathrm{AP}^{\prime}$ ye erişen akıllı telefonların bağlantı süresi verileri bulunmamaktadır. Dolayısıyla, bu veriler kümesinde bazı ön işlemleri uygulamak gereklidir. İlk işlem; alakasız verilerin silinmesi, Handover efekti silinmesi, BS veya AP ile kullanıcıların bağlantı sürelerinin saptanması veya düzeltilmesidir. El değiştirme problemi akıllı telefon için elimine edilebilir. Bu problemi ortadan kaldırmak için yapılacak ilk adım, kullanıcının iletişim kurduğu BS'ler arasındaki uzaklığın tespitidir [15]. Sonrasında BS ve AP bağlantı verilerinin ve bunların haberleşme aralığının incelenmesi sonucunda, $T_{B S_{M A X}}$ ve $T_{W F_{M A X}}$ 'nin sistem parametrelerinin sırasıyla otuz ve beş dakika ile en iyi sonuca ulaştı̆̆ 1 tespit edilmiştir. BS veya AP için Handover etkisini ortadan kaldırmak için iki kural vardır:

$$
\begin{aligned}
d^{B S} \leq 5 \mathrm{~km} \text { or } d^{W F} \leq 100 m \text { ve } \\
\\
\Delta T_{i}<T_{B S_{M A X}} \text { or } \Delta T_{j}<T_{W F_{M A X}}
\end{aligned}
$$

Burada $\Delta T_{i}$ iki BS verisi arasındaki zaman farkı, $\Delta T_{j}$ ise iki AP verisi arasındaki zaman farkıdır. Bir diğer önemli parametre bağlantı süresinin uzunluğudur. Zaman farkı iki şekilde belirlenebilir: (i) akıllı telefon kullanıcısı mobil değildir ve bu kullancının 30 dakika içinde aynı BS'ye tekrar bağlanma, (ii) bir akıllı telefon kullanıcısının 5 dakika içerisinde aynı AP'ye yeniden mobil olarak bağlanamama durumudur. $\mathcal{D}_{i}^{B S}$ veya $\mathcal{D}_{j}^{W F}$; i' ninci veya j'ninci enlemi ve boylamı olarak ayarlanmıştır. $\Delta t ; t_{2}-t_{1}+\Delta t_{2}$ şeklinde hesaplanmıştır. $\mathcal{D}_{i+1}^{B S}$ or $\mathcal{D}_{j+1}^{W F}$ içeren ve $\mathcal{D}_{i}^{B S}$ veya $\mathcal{D}_{j}^{W F}$ ve $\mathcal{D}_{i+1}^{B S}$ veya $\mathcal{D}_{j+1}^{W F}$ arasında kalan bütün veriler silinmiştir. Yukarıdaki işlemlerin sonucu olarak, el değiştirme etkisi ortadan kalkmıştır. Kentin veya binanın yoğun nüfus alanları, hiyerarşik kümeleme tekniği ile bulunmuştur [15]. Nüfus yoğunluğunun karar kriteri, bulunulan bölgedeki kullanıcıların BS'lerine veya AP'lerine yapılan bağlantı sayısıdır. Bağlantıların sayısının artması genel olarak nüfusun çok olduğuna işaret etmektedir. $\mathrm{Bu}$ platformda, yüksek yoğunluklu nüfus bölgeleri, bir felâketi yönetmek için kümeleme yoluyla incelenmektedir. Kümeleme sürecinde, BS'lerin ve AP'lerin sayısı ve BS'lere ve AP'lere ulaşan akıllı telefonların sayısı bulunmaktadır. Bilinen her BS ve AP için, günlük olarak bağlı olan kullanıcı sayısı belirlenir. Bağlanan kullanıcıların sayısı, kümeleme işlemi için bir ağırlık olarak dikkate alınır. Bu işlem başlamadan önce her küme için ağırlıklı bir merkez noktası ayarlanır. En kısa aralıktaki iki küme, her bir kümeleme işleminde bir kümeye birleştirilir. İki kümenin merkezleri arasındaki mesafe aşağıdaki denklemler ile gösterilmektedir:

$$
\begin{aligned}
& \varphi_{c}=\frac{\left(u s e r_{-} n_{1}\right)\left(\varphi_{c}^{1}\right)+\left(u s e r_{-} n_{2}\right)\left(\varphi_{c}^{2}\right)}{u s e r_{-} n_{1}+u s e r_{-} n_{2}} \mathrm{ve} \\
& \lambda_{c}=\frac{\left(u s e r_{-} n_{1}\right)\left(\lambda_{c}^{1}\right)+\left(u s e r_{-} n_{2}\right)\left(\lambda_{c}^{2}\right)}{u s e r_{-} n_{1}+u s e r_{-} n_{2}} \\
& u s e r_{-} n_{c}=u s e r_{-} n_{1}+u s e r_{-} n_{2}
\end{aligned}
$$

Burada user_n $n_{c}$; BS'ye ulaşan akıllı telefon kullanıcılarının sayısıdır. , $\varphi_{c}$ ve $\lambda_{c}$; sırasıyla küme merkezinin enlem ve boylamını temsil eder. İlk olarak, her BS veya AP bir küme olarak belirlenir. $\mathrm{Bu}$ nedenle, her kümenin merkez noktası bir BS veya bir AP'nin koordinatlarıdır ve ağırlık değeri 1 olarak alınır. İki küme daha sonra en kısa mesafe ile birleştirilir. $\mathrm{Bu}$ işlem eşik mesafesi karşılanıncaya ve ardından birleşme tamamlanıncaya kadar devam eder. Her akıllı telefon veya Wi-Fi kullanıcısı ayrı olarak değerlendirildiğinden, işleme ve veri saklama bir kaç bilgisayar üzerinde paralel yapılmaktadır. $\mathrm{Bu}$ nedenle, önerilen afet yönetim sisteminde Apache Spark ve Hadoop Dağıtılmış Dosya Sistemi (HDFS) değerlendirilmektedir. Apache Spark, büyük ölçekli veri işleme için hızlı ve yaygın bir motordur [16]. Spark, gelişmiş ve ek özellikler sağlamak için mevcut HDFS altyapısının üstünde çalışır. HDFS tüm BS ve AP bağlantı verilerini saklamak için kullanılır. Bu veriler Apache Spark tarafindan incelenmiş ve işlenmiştir [17]. Ayrıca birkaç açık kaynak geliştirme ortamı içeren Python paketlerinden Anaconda kullanılmıştır. Ayrıca, JDK 8 geliştirme ortamı HDFS ve Apache Spark ile birlikte kullanılmaktadir.

\subsection{Bulanık Mantık Tabanlı Karar Destek Sistemi}

Afet Sonrası Yönetim Sisteminin temel amacı kurtarma kaynaklarını adil ve verimli bir şekilde yönetmektir. Literatürde afet yönetim sistemlerinde kullanılan yöntemlerden biri olduğu için karar destek sistemi olarak bulanık mantık tercih edilmiştir [18-20]. Kullanılan bulanık temelli karar destek sistemi Şekil 6'da verilmektedir. Karar destek sistemi afet bölgesindeki bir yapıya ait hasar bilgileri (yön, yıkım mesafesi vb.) ile bölgedeki insan yoğunluk bilgisine dayalı olarak kurtarma kaynaklarının kullanımına karar verir.

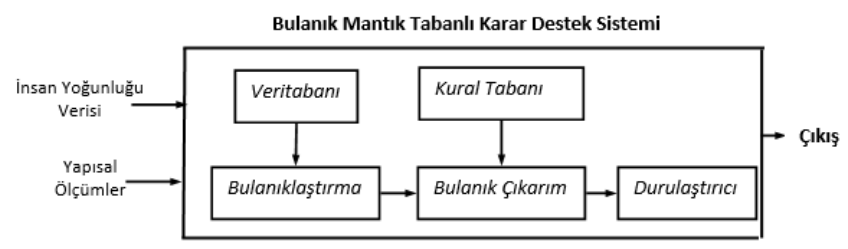

Şekil 6. Önerilen bulanık mantık tabanlı karar destek sisteminin blok diyagramı 
Bulanık mantık tabanlı karar destek sistemi üç ana bölümden oluşmaktadır. Bunlar; bulanıklaştırma, bulanık çıkarım ve durulaştırıcı bölümleridir. Bulanıklaştırma, bina ve insan yoğunluk bilgilerinin durum verilerine ait yapısal ölçüleri bulanık sete dönüştürür. Bulanık set, uygun üyelik fonksiyonları olan dil değişkenlerinden oluşur [18-21]. Tablo 1'de dilsel değişkenlerden oluşan bulanık kurallar verilmektedir.

Tablo 1. Önerilen bulanık mantık tabanlı karar destek sisteminin kural tabanı

\begin{tabular}{|c|c|c|c|}
\hline Eğer & İnsan Sayısı & Hasar Durumu & Çıkış \\
\hline 1 & az & düşük & acil değil \\
\hline 2 & $\mathrm{az}$ & orta & acil değil \\
\hline 3 & $\mathrm{az}$ & yüksek & acil \\
\hline 4 & orta & düşük & acil değil \\
\hline 5 & orta & orta & acil \\
\hline 6 & orta & yüksek & acil \\
\hline 7 & çok & düşük & acil \\
\hline 8 & çok & orta & acil \\
\hline 9 & çok & yüksek & çok acil \\
\hline
\end{tabular}

Şekil 7 ve 8, sırasıyla bulanık üyelik fonksiyonlarını göstermektedir. Üyelik fonksiyonları türleri Trimf ve Trapmf olarak seçilmiştir. Bu türler, bu çalışmada girdi ve çıktı değerine uygundur. Ayrıca, Trimf ve Trapmf gerçek zamanlı uygulamalar için daha iyi performansa sahiptir [21].

$\mathrm{Bu}$ sistemde iki giriş ve bir çıkış vardır. Girdi değerleri, afet bölgesindeki insan yoğunluğu bilgisi ve binanın hasar durumudur. Çıktı, Şekil 9'da görüldüğü gibi sonuç değeri olarak adlandırılır. Afet bölgesinde yerleşik insan yoğunluğu bilgisi, üç üyelik işlevine sahiptir. Bunlar az, orta ve çoktur. Benzer şekilde, diğer girdi olan bina hasar durumu da üç üyelik işlevine sahiptir: düşük, orta ve yüksek. Ayrıca, çıktı acil değil, orta ve acil olmak üzere üç üyelik işlevine sahiptir.

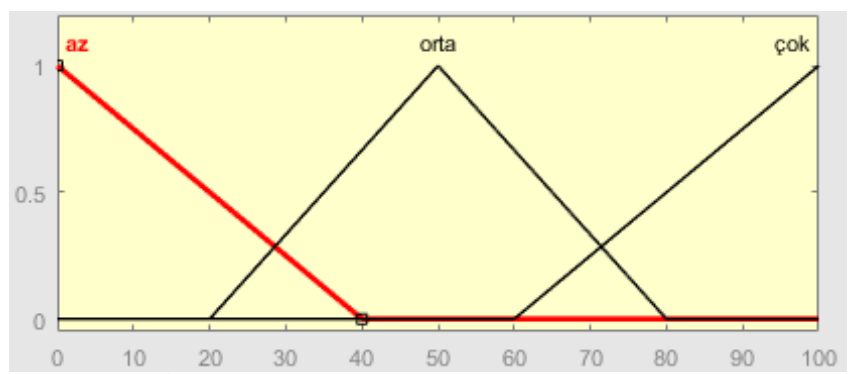

Şekil 7. İnsan yoğunluğu girişinin üyelik fonksiyonları

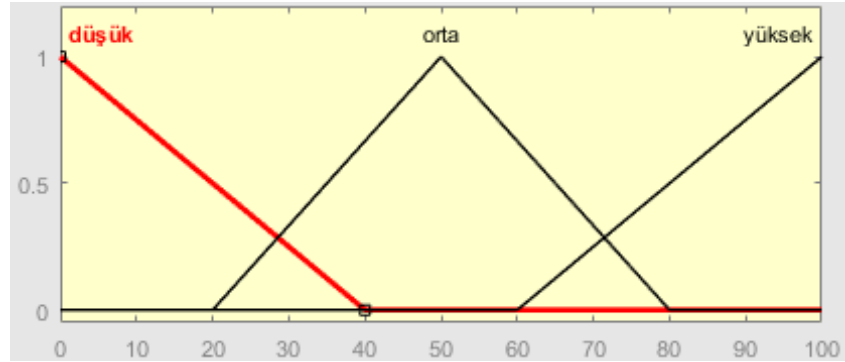

Şekil 8. Bina hasar durumu girişinin üyelik fonksiyonları

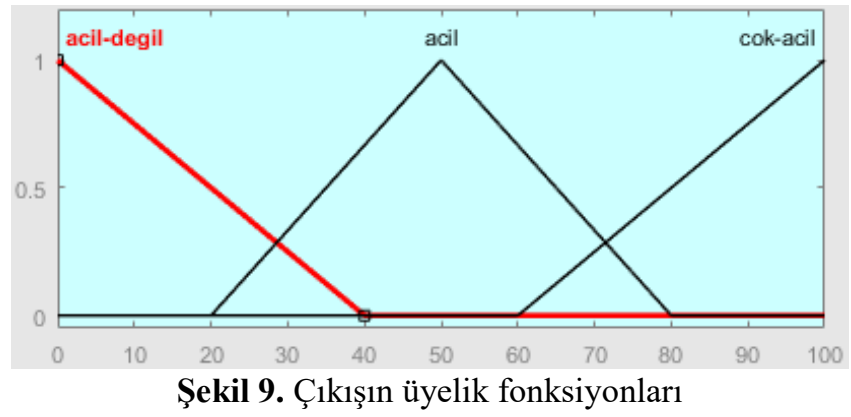

\section{AFET SONRASI YÖNETIM SISTEMININ KULLANILDIĞI ÖRNEK SENARYO}

Geliştirilen Afet Sonrası Yönetim Sisteminin kullanılırlığının ve sağlayacağı faydaların analizi için örnek bir senaryo geliştirilmiştir. Örnek senaryo kapsamında bazı durumlar varsayım olarak kabul edilmiştir. $\mathrm{Bu}$ senaryoda Sakarya Üniversitesi Kampüsü afet bölgesi olarak alınmıştır. Diğer varsayım ve kabul edilen koşullar şunlardır:

- Kampüsün yaklaşık $5 \mathrm{~km}$ içerisindeki yedi baz istasyon kulesi var olduğu,

- Üniversite kampüsündeki 50 Wi-Fi erişim noktasının kullanıldığı,

- Tasarlanan dört IoT nesnesinin konuşlandırılmış ve altı sanal IoT nesnesi dağıtıldığ 1 varsayılmıştır.

- $\quad$ IoT nesneleri, her 24 saatte bir ivmeölçer verilerini ölçer ve konumları arasında bir fark olması durumunda bu verileri IoT analiz platformuna gönderir.

- IoT nesneleri, Wi-Fi veya GSM teknolojilerini kullanarak sisteme bağlanabilir.

- Sakarya Üniversitesi Kampüsü'nde, bir hafta boyunca Baz İstasyonlar ve Wi-Fi Erişim Noktaları ile akıllı telefonlar aracılığıyla veri seti için kullanılmıştır.

Afet Sonrası IoT Yönetim Platformu insan yoğunluğu, hasar bilgisi gibi farklı bilgileri göz önüne alarak afet sonrası yönetiminin hızlı ve etkili kararlar almasına yardımcı olan güçlü bir araçtır. Şekil 10'da afet bölgesi içerisindeki insan yoğunluğu görülmektedir. Önerilen sistemimizde, Şekil 11 'de harita yakınlaştırma düzeylerine göre sınıflandırılarak ve ağ verisi veya mobil ağ verisi ve Wi-Fi bağlantı verileri ile belirlenmiştir. Örnek senaryoda, tespit edilen farklı hasar seviyesi ve yerleşik yoğunluk farklı renklerle gösterilmektedir. Kullanıcı ara yüzünde, hasar seviyesi üç farklı renkle gösterilmektedir. 
Yeşil bölge herhangi bir hasar olmadığını, sarı alanda hasar gören bazı yapıların bulunduğu ve kırmızı bölge tüm yapıların hasar gördüğü ifade edilmektedir. Bu renkli dairelerin genişliği, nüfus yoğunluğunu temsil etmektedir. $\mathrm{Bu}$ grafiksel gösterim ile hızlı ve doğru karar alınması sağlanmaktadır. Özetle, kırmızı bölgede daha büyük bir hasarın olduğu ve yaklaşık 2000 kişinin o alanda bulunduğu görülmektedir.

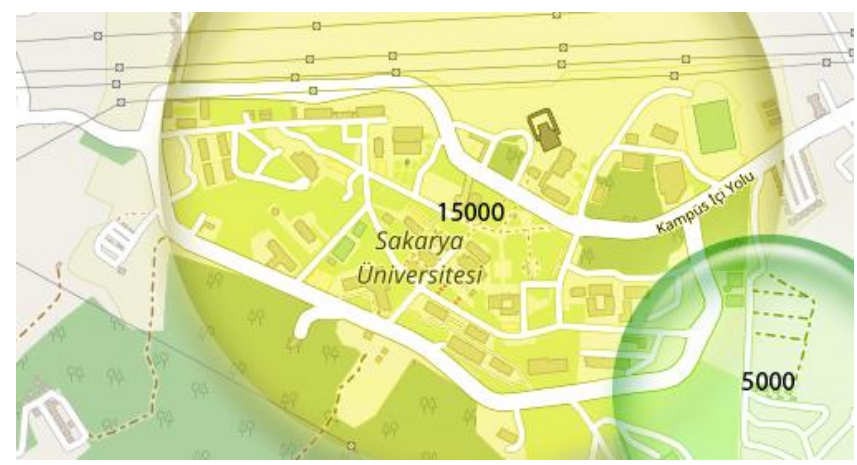

Şekil 10. Kümeleme - renk olarak temsil edilen, hücresel ağ verilerini kullanarak afet alanını gösteren bir harita.

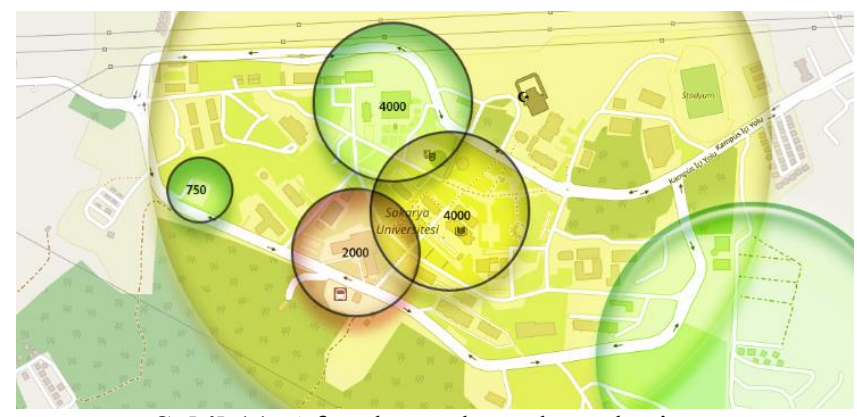

Şekil 11. Afet alanını kümeleme haritası

\section{SONUÇ}

Doğal ya da doğal olmayan bir afet durumu meydana geldikten sonra afetin etkilerinin en aza indirilmesi, afet bölgesine ait verilerin doğru ve hızlı bir şekilde alınması ile sağlanabilir. $\mathrm{Bu}$ durum Afet Sonrası Yönetim Sistemleri etkin ve verimliliği için büyük önem arz eder.

$\mathrm{Bu}$ amaçla, makalede nesnelerin interneti teknolojisini kullanan bir Afet Sonrası Yönetim Sistemi önerilmiştir. Nesnelerin interneti teknolojisi ile afet bölgesindeki hasar durumu ve afetten etkilenen insan sayısı gibi en önemli iki temel bilgi elde edilmektedir. Ayrıca bu bilginin bulanık mantık tabanlı karar destek sistemi ile işlenerek afet sonrası süreçlerin ve kurtarma ekipleri, araç-gereç vb. kaynakların daha verimli yönetimi amaçlanmaktadır.

\section{Teşekkürler}

$\mathrm{Bu}$ çalışma, Sakarya Üniversitesi Bilimsel Araştırma Projeleri Komitesi (SAU-BAPK) tarafından desteklenmiştir. (Grant No. 2017-12-10-010.)

\section{KAYNAKÇA}

[1] K. Kucuk, C. Bayilmis, A.F. Sonmez, S. Kacar, "Internet of Things Based Disaster Management System Design and Implementation", $2^{\text {nd }}$ International Symposium on Natural Hazards and Disaster Management ISHAD 2018, Sakarya, 562-571, (2018).

[2] N. Tantitharanukul, K. Osathanunkul, K. Hantrakul, P. Pramokchon, P. Khoenkaw, "A review on using soft computing techniques in disaster management and risk assessment", $1^{\text {st }}$ International Conference on Innovation and Challenges in Cyber Security ICICCS 2016, India, 119-122, (2016).

[3] P. Sakhardande, S. Hanagal, S. Kulkarni, "Design of disaster management system using IoT based interconnected network with smart city monitoring", International Conference on Internet of Things and Applications IOTA, Pune, India, 185-190, 2016.

[4] A. Fuqaha, M. Guizani, M. Mohammadi, M. Aledhari, M. Ayyash, "Internet of Things: A Survey on Enabling Technologies, Protocols, and Applications", IEEE Commun. Surveys Tuts, vol. 17, no. 4, pp. 2347-2376, June 2015.

[5] L. Atzori, A. Iera, and G. Morabito, "The internet of things: A survey", Comput. Netw., vol. 54, no. 15, pp. $2787-$ 2805, Oct. 2010.

[6] A. Zanella, N. Bui, A. Castellani, L. Vangelista, M. Zorzi, "Internet of Things for Smart Cities", IEEE Internet of Things Journal, vol. 1, no. 1, pp. 22-32, Feb. 2014.

[7] S. Poslad, S. E. Middleton, F. Chaves, R. Tao, O. Necmioglu, U. Bügel, "A Semantic IoT Early Warning System for Natural Environment Crisis Management", IEEE Trans. Emerging Topics in Computing, vol. 3, no. 2, pp. 246-257, June 2015.

[8] I. Benkhelifa, N. Taboudjemat, S.Moussaoui, "Disaster Management Projects using Wireless Sensor Networks: An Overview" $28^{\text {th }}$ International Conference on Advanced Information Networking and Applications AINA 2014, Canada, 605-610, (2014).

[9] A. S. Bhosle and L. M. Gavhane, "Forest disaster management with wireless sensor network" International Conference on Electrical, Electronics, and Optimization Techniques ICEEOT, India, 287-289, (2016).

[10] M. Kamruzzaman, N. Sarkar, J. Gutierrez, S. K. Ray, "A study of IoT-based post-disaster management", $31^{\text {st }}$ International Conference on Information Networking ICOIN 2017, Vietnam, 406-410, (2017).

[11] MQTT, URL: http://mqtt.org (Erişim zamanı; Şubat, 1, 2017)

[12] ISO/IEC20922:2016. MQTT v.3.1.1., URL: https://webstore.iec.ch/publication/25096\&preview=1

(Erişim zamanı; Şubat 8, 2017)

[13] C. Bayilmis et al., "The design and implementation of remote personel monitoring system in military zones", 12th International Conference on Electronics, Computer and Computation ICECCO2015, Almat1, Kazakistan, 1-4, (2015).

[14] A.Sevin, C. Bayilmis, I. Erturk, H. Ekiz, and A. Karaca, "Design and Implementation of a Man-Overboard Emergency Discovery System Based On Wireless Sensor 
Networks", Turk J Elec Eng \& Comp Sci, vol. 24, no. 3, pp. 762-773, June 2016.

[15] Y. Guo, J. Zhang, and Y. Zhang, "An Algorithm for Analyzing the City Residents' Activity Information through Mobile Big Data Mining", The 10th IEEE International Conference on Big Data Science and Engineering (2016 IEEE Trustcom/BigDataSE/ISPA), Tianjin, China, 21332138, (2016).

[16] E. Ivannikova, "Scalable implementation of dependence clustering in Apache Spark", 2017 Evolving and Adaptive Intelligent Systems (EAIS), Ljubljana, 1-6, (2017).

[17] Apache hadoop, URL: http://hadoop.apache.org/ (Erişim zamanı; Şubat, 21, 2017)

[18] P. Zlateva, D. Velev, "Complex Risk Analysis of
Natural Hazards through Fuzzy Logic", Journal of Advanced Management Science, vol. 1, no. 4, pp. 395-400, Dec. 2013. [19] W-K. Chen, G. Sui, D. Tang, "A fuzzy intelligent decision support system for typhoon disaster management", 2011 IEEE Intertanional Conference on Fuzzy Systems (FUZZ-IEEE 2011), Taiwan, 364-367, (2011).

[20] P. Zlateva, L. Pashova, K. Stoyanov, D. Velev, "Social Risk Assessment from Natural Hazards Using Fuzzy Logic", International Journal of Social Science and Humanity, vol. 1, no.3, pp.193-198, Sept. 2011.

[21] A. Çalhan, C. Çeken, "An Optimum Vertical Handoff Decision Algorithm Based on Adaptive Fuzzy Logic and Genetic Algorithm",Wireless Personal Commun., vol. 64, no. 4, pp. 647-664, June 2012. 